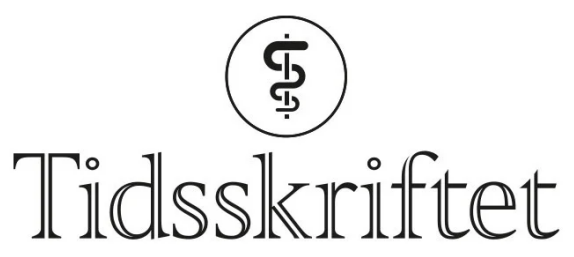

DEN NORSKE LEGEFORENING

\title{
Når pasienten er idrettsutøver
}

KRONIKK

PER M. THORSBY

pertho@ous-hf.no

Per M. Thorsby er seksjonsoverlege ved Hormonlaboratoriet ved Oslo universitetssykehus. Han er spesialist i endokrinologi, ph.d. i diabetes- og overvektsgenetikk og leder av medisinsk fagkomité i Antidoping Norge.

Forfatter har fylt ut ICMJE-skjemaet og oppgir følgende interessekonflikt: Han mottar honorar fra Antidoping Norge.

\section{ASTRID GJELSTAD}

Astrid Gjelstad er cand.pharm. og ph.d. i legemiddelanalyse. Hun er medisinsk fagrådgiver i Antidoping Norge og har i tillegg en bistilling som førsteamanuensis ved seksjon for farmasøytisk kjemi ved Universitetet i Oslo.

Forfatter har fylt ut ICMJE-skjemaet og oppgir følgende interessekonflikt: Hun mottar honorar fra Antidoping Norge.

\section{Pasienter kan være idrettsutøvere og dermed underlagt Verdens antidopingbyrås (World Anti-Doping Agency, WADA) antidopingregelverk - noen ganger uten å være klar over det selv. Da kan det være til stor hjelp at behandlende lege har kunnskap om regelverkets retningslinjer for medisinsk behandling.}

Som ansvarlige for det medisinske området i Antidoping Norge er vårt generelle inntrykk at det er begrenset med kunnskap om legemiddelbruk i antidopingsammenheng for leger og annet helsepersonell som ikke daglig jobber med denne pasientgruppen.

\section{Idrettsutøvere og antidopingregler}

Det er den uavhengige stiftelsen Antidoping Norge som forvalter dopingreglementet for norsk idrett. I Norge er alle medlemmer av klubber og idrettslag tilsluttet Norges idrettsforbund (NIF) og deltakere i idrettsarrangement arrangert av et organisasjonsledd i NIF underlagt dopingreglementet (1). Med ca. 1,3 millioner medlemmer i NIF, er en stor andel av Norges befolkning forpliktet til å følge dopingreglementet, og det er ikke til å legge skjul på at svært mange ikke vet hva dette innebærer. Selv om toppidrettsutøvere, som omfatter ca. 4 ooo-5 ooo utøvere i Norge, er underlagt større forpliktelser ved 
medisinsk behandling, bør alle utøvere over 15 år som deltar i organisert idrett ha kunnskap om hva som kreves dersom det brukes legemidler som står på Verdens

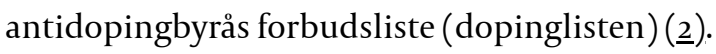

\section{"Har man mulighet til å endre behandling slik at pasienten ikke trenger å bruke legemidler som inneholder stoffer på dopinglisten, er dette det enkleste både for lege og utøver»}

Det internasjonale antidopingarbeidet startet for alvor på 6o- og 7o-tallet, fordi man så at dopingproblematikken utgjorde en betydelig helserisiko for utøver. Før forbudet mot stimulerende stoffer og narkotika kom i 1967, var det utøvere som omkom underveis i konkurranse på grunn av ukontrollert bruk av stimulerende midler (3). Helseperspektivet er derfor et vesentlig punkt i antidopingarbeidet, og dette reflekteres blant annet i vurderingene om et stoff eller metode skal settes på dopinglisten. Kriteriene for å komme på denne listen er at minst to av følgende tre kriterier er oppfylt: Bruk av stoffet eller metoden kan ha et prestasjonsfremmende potensial, bruk av stoffet eller metoden kan være helseskadelig for utøver, eller bruk av stoffet eller metoden skader idrettens anseelse (4). I tillegg er det forbudt med stoffer eller metoder som kan maskere bruk av andre prestasjonsfremmende stoffer. Noen stoffer og metoder er alltid forbudt (gruppe So-S5 (Tabell 1) og M1-M3 (Tabell 2)), mens andre kun er forbudt i konkurranse (gruppe S6-S9 (Tabell 3)). I tillegg kommer stoffer som bare er forbudt i visse idrettsgrener, slik som for eksempel betablokkere ved skyting (gruppe P1).

\section{Tabell 1}

Dopinglisten, stoffer forbudt i og utenfor konkurranse

\begin{tabular}{|lll|}
\hline Gruppe & OOC (out of competition, totalforbudt) & Eksempel, legemiddel \\
\hline S0 & Stoffer i eksperimentell/utprøvende fase & \\
\hline S1 & Anabole stoffer & Testosteron \\
\hline S2 & $\begin{array}{l}\text { Peptidhormoner, vekstfaktorer og relaterte } \\
\text { substanser og mimetika }\end{array}$ & Veksthormon, EPO \\
\hline S3 & B2-agonister & Salbutamol, formoterol \\
\hline S4 & Hormon- og metabolske modulatorer & Insulin \\
\hline S5 & Diuretika og maskeringsmidler & Hydroklortiazid, furosemid \\
\hline
\end{tabular}

\section{Tabell 2}

Dopinglisten, forbudte metoder (forbudt i og utenfor konkurranse)

\begin{tabular}{|c|c|c|}
\hline Gruppe & Metoder & Eksempel \\
\hline M1 & Manipulering av blod og blodkomponenter & Blodoverføringer \\
\hline M2 & Kjemisk og fysisk manipulering & $\begin{array}{l}\text { Intravenøs infusjon på mer enn } \\
100 \text { mL pr } 12 \text { timer }^{1}\end{array}$ \\
\hline M3 & Gendoping & \\
\hline
\end{tabular}


${ }^{1}$ Unntatt som ledd i sykehusbehandling, kirurgiske prosedyrer eller klinisk diagnostiske undersøkelser.

\section{Tabell 3}

Dopinglisten, stoffer kun forbudt i konkurranse

\begin{tabular}{|c|c|c|}
\hline Gruppe & IC (in competition, forbudt i konkurranse ${ }^{1}$ ) & Eksempel, legemiddel \\
\hline S6 & Stimulerende midler & Metylfenidat \\
\hline S7 & Narkotiske stoffer & Morfin \\
\hline S8 & Cannabinoider (cannabis) & Tetrahydrocannabinol \\
\hline S9 & Glukokortikoider (systemisk bruk) & Prednisolon, triamcinolon \\
\hline P1 & Betablokkere $^{2}$ & Metoprolol $^{2}$ \\
\hline
\end{tabular}

${ }^{1}$ Skal ikke være i kroppen i en konkurranse.

${ }^{2}$ Forbudt innen enkelte idretter.

\section{Trenger min pasient å søke om medisinsk fritak?}

Dersom pasienten er omfattet av antidopingregelverket, må man finne ut om legemidlet pasienten trenger inneholder stoffer som står på dopinglisten. Brukes det norskregistrerte legemidler, er dette enkelt å finne ut av ved å søke opp legemidlet i Felleskatalogen eller på nettsidene til Antidoping Norge. Bruk av silhuetter (Figur 1) med ulike farger gjør det enkelt for brukere av Felleskatalogen å være oppmerksomme på om det er knyttet dopingproblematikk til de enkelte legemidlene.
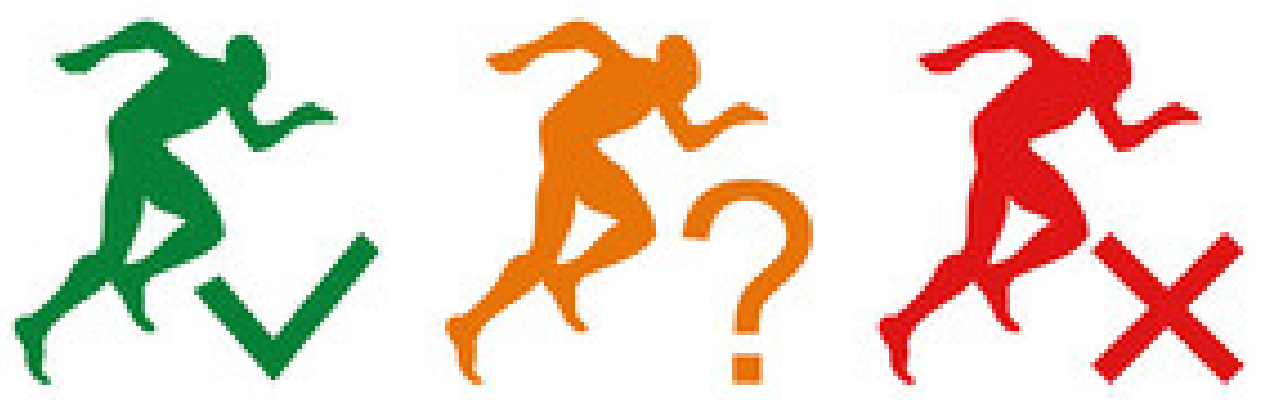

Figur 1 Grønn silhuett betyr at legemidlet er tillatt å bruke uten restriksjoner, gul silhuett innebærer et forbud med visse unntak, mens rød silhuett betyr at legemidlet inneholder stoffer som står på dopinglisten. Figur: Antidoping Norge / Felleskatalogen Har man mulighet til å endre behandling slik at pasienten ikke trenger å bruke legemidler som inneholder stoffer på dopinglisten, er dette det enkleste både for lege og utøver. Dersom dette ikke er mulig må man eventuelt søke om medisinsk fritak for bruk av legemidlet. Søknaden fylles ut av utøver og behandlende lege i fellesskap og sendes til Antidoping Norge eller et internasjonalt særforbund, hvor den blir vurdert av en medisinsk fagkomité (ramme 1). 
Ramme 1 For at utøver skal få godkjenning for å bruke legemidler som inneholder stoffer som står på dopinglisten må følgende kriterier være oppfylt (5):

a) Det forbudte stoffet/metoden det er snakk om, er nødvendig for å behandle en diagnostisert medisinsk tilstand.

b) Det forbudte stoffet/metoden brukt i medisinsk behandling gir med sannsynlighetsovervekt ingen kjent prestasjonsforbedring utover det som kan forventes ved en tilbakevending til utøverens normale helsetilstand etter behandling av den medisinske tilstanden.

c) Det forbudte stoffet/metoden er en indisert behandling av den medisinske tilstanden, og det er ingen annen rimelig og fornuftig tillatt terapeutisk behandling.

d) Bruk av legemiddel som inneholder det forbudte stoffet/metoden skal ikke være en konsekvens av tidligere ulovlig bruk av forbudte stoffer/metoder.

Hvis ett av disse kriteriene ikke er oppfylt, kan legemidlet i utgangspunktet ikke godkjennes for bruk i idrett.

Fagkomitéen i Antidoping Norge er sammensatt av ulike legespesialiteter, for tiden innen endokrinologi, psykiatri, lungemedisin, pediatri og idrettsmedisin. Habilitet og uavhengighet er viktig for Antidoping Norge, og ingen av medlemmene i komiteen har derfor tunge verv i norsk idrett. Når søknadene om medisinsk fritak behandles, er det viktigste argumentet for godkjenning at de fire kriteriene nevnt over er oppfylt. Det utøves også skjønn i hvert enkelt tilfelle, men den skjønnsmessige vurderingen er begrenset av Verdens antidopingbyrås regelverk og veiledning (5).

Utøvernivå har avgjørende betydning for når og hvor man skal søke om medisinsk fritak. Dersom utøver er definert som nasjonal (므) eller internasjonal topputøver, må det sendes inn søknad så snart diagnose foreligger. Dersom en utøver ikke er definert som internasjonal eller nasjonal topputøver, kan man søke om medisinsk fritak i etterkant av for eksempel en positiv dopingprøve, såkalt retroaktivt fritak, når Antidoping Norge ber om det (7.). Alle utøvere må imidlertid påse at kriteriene for å få innvilget fritak er oppfylt, uavhengig av om man søker prospektivt eller retroaktivt. De fleste norske utøvere kan få behandlet sin søknad av Antidoping Norge, mens enkelte toppidrettsutøvere må få sine søknader behandlet av internasjonale særforbund eller andre internasjonale aktører (for eksempel den internasjonale olympiske komité). Vedtak allerede gjort av Antidoping Norge skal i prinsippet også gjelde for de internasjonale særforbundene, men en slik anerkjennelse skjer ikke automatisk. De ulike særforbundene har ulike regler for dette, og gjeldende regler må avklares i hvert enkelt tilfelle - gjerne med bistand fra Antidoping Norge. Alle vedtak er tidsbegrenset (7.).

\section{Hypogonadisme, astma og injeksjonssteroider}

Tilstrekkelig med medisinske opplysninger er nødvendig for behandling av en søknad om medisinsk fritak. Det er klare føringer fra Verdens antidopingbyrå til hva som kreves av medisinske opplysninger om diagnose for ulike tilstander (ㅁ). For eksempel kreves det dokumentasjon av konkret organisk lidelse dersom det søkes om bruk av testosteron. I praksis betyr dette at man enten må ha en alvorlig hypofyse- eller testikkelsykdom. En lav testosteronverdi målt i blod er ikke nok. For diagnosen astma kreves det spirometri med reversibilitetstest. Er denne negativ kreves det positiv bronkialprovokasjonstest. Dersom andre beta-2-agonister enn salbutamol, salmeterol, vilanterol eller formoterol benyttes, skal det fremgå en forklaring på hvorfor alternativ beta-2-agonist er forskrevet. 
Det har vært tradisjon for å bruke triamcinoloninjeksjoner ved sesongallergi. Internasjonale medisinske retningslinjer fraråder bruk av steroidinjeksjoner $\mathrm{i}$ allergibehandling, blant annet på grunn av manglende dokumentasjon på effekt og risiko for bivirkninger (9.). Det er blant annet vist at langvarig påvirkning av kortikosteroider kan føre til muskelsvinn (10), som åpenbart ikke er en fordel for idrettsutøvere. Retningslinjene åpner for en kort kur (et par dager) med orale kortikosteroider i tilfeller hvor man har uttalte plager og ikke kommer i mål med annen medikamentell behandling. Man anbefaler imidlertid spesifikk immunterapi (allergivaksinasjon) som behandling for alvorlig allergi. Siden det finnes andre alternativer for behandling, er derfor kriterium c) i kriteriene for å få innvilget medisinsk fritak ikke oppfylt i mange tilfeller.

\section{«Det får store konsekvenser for en idrettsutøver å bli dopingtatt»}

Bruk av lokale glukokortikoidinjeksjoner og smertestillende legemidler i idrett er et tema som blir omtalt i media med jevne mellomrom $(\underline{11}, \underline{12})$. Selv om dette som regel gjelder legemidler som inneholder tillatte stoffer i henhold til dopinglisten, for eksempel ikkesteroide antiinflammatoriske midler, er det en bekymring at smertestillende legemidler brukes for eksempel for å kunne gjennomføre en kamp/konkurranse. Dette er en problematikk som bør diskuteres og hensyntas av medisinsk støttepersonell, slik at utøvere ikke blir fullstendig overlatt til seg selv med selvmedisinering og de konsekvensene det kan få. En vesentlig årsak til at antidopingarbeidet ble igangsatt var behovet for å beskytte utøvernes helse (3), og riktig legemiddelbruk i idretten inngår etter vårt syn i dette perspektivet. Det er også nedfelt i «Etiske retningslinjer for helsepersonell i norsk idrett", utarbeidet av idrettsmedisinsk etikkutvalg, at "helsepersonell skal verne utøvernes helse, gjennom å forebygge sykdom og skade og å hjelpe syke eller skadde utøvere til å gjenvinne sin helse - og at utøverens helse skal ligge til grunn for helsepersonellets valg og råd». Videre fastslås det at «behandlinger som utelukkende har som mål å øke idrettsprestasjoner ikke ligger innenfor helsepersonellets oppgaver» (13).

\section{Konklusjon}

Det stilles strenge krav til at alle konkurranser skjer på like vilkår. Antidoping Norge jobber daglig med å legge til rette for at regelverket formidles på en forståelig og korrekt måte, både for utøvere, pårørende og støttepersonell. Det får store konsekvenser for en idrettsutøver å bli dopingtatt. God medisinsk praksis og hjelp med å håndtere bruk av legemidler som står på dopinglisten på en korrekt måte vil i betydelig grad begrense denne risikoen. Leger som behandler idrettsutøvere bør sette seg godt inn i regelverket for medisinsk behandling av denne pasientgruppen.

LITTERATUR

1. Lov for Norges idrettsforbund og olympiske og paralympiske komité. Oslo: Norges idrettsforbund, 2020. https://www.idrettsforbundet.no/globalassets/idrett/juss/lover/nifs-lov-1.1.2021.pdf Lest 16.2.2021.

2. The World Anti-Doping Code. International Standard Prohibited List 2021. Quebec: World AntiDoping Agency, 2021. https://www.wada-ama.org/sites/default/files/resources/files/2021list_en.pdf Lest 2.12.202O.

3. Mottram DR, Chester N. Drugs in sport. 7. utg. Routledge, 2018.

4. World Anti-Doping Code 2015 with 2019 Amendments. Quebec: World Anti-Doping Agency, 2019. https://www.wada-ama.org/sites/default/files/resources/files/wada_anti- 
doping_code_2019_english_final_revised_v1_linked.pdf Lest 28.8.2020.

5. The World Anti-Doping Code International Standard For Therapeutic Use Exemptions. Quebec: World Anti-Doping Agency, 2021. https://www.wada-

ama.org/sites/default/files/resources/files/international_standard_istue_-_2020.pdf Lest 13.8.2020.

6. Antidoping Norge. Toppidrettsutøverliste.

https://www.antidoping.no/regler/toppidrettsut\%C3\%B8verliste Lest 3.12.2020.

7. Antidoping Norge. Medisinske fritak (TUE). https://www.antidoping.no/medisinsk/medisinskfritak-tue Lest 3.12.2020.

8. World Anti-Doping Agency. Medical information to support the decisions of TUECs. https://www.wada-ama.org/en/resources/search?f\%5Bo\%5D=field_resource_collections\%3A158\#list Lest 3.12.2020.

9. Brożek JL, Bousquet J, Agache I et al. Allergic Rhinitis and its Impact on Asthma (ARIA) guidelines2016 revision. J Allergy Clin Immunol 2017; 140: 950-8. [PubMed][CrossRef]

10. Vernec A, Slack A, Harcourt PR et al. Glucocorticoids in elite sport: current status, controversies and innovative management strategies-a narrative review. Br J Sports Med 2020; 54: 8-12. [PubMed] [CrossRef]

11. Høidalen I. Slår alarm om smertestillende i idretten: - Jeg tok Voltaren hver dag. VG 1.12.202O. https://www.vg.no/sport/i/eK8kVa/slaar-alarm-om-smertestillende-i-idretten-jeg-tok-voltaren-hverdag Lest 16.2.2021.

12. Høidalen I. Løkberg om kortisonbruk:-Angrer. VG 1.12.2020.

https://www.vg.no/sport/i/AllmLz/loekberg-om-kortisonbruk-angrer Lest 16.2.2021.

13. Norsk idretssforbund. Etiske retningslinjer for helsepersonell i norsk idrett. https://www.idrettsforbundet.no/contentassets/f283dob88ao84569a81fdd33ecc8373b/etiskeretningslinjer-for-helsepersonell-i-norsk-idrett.pdf Lest 16.2.2021.

Publisert: 26. april 2021. Tidsskr Nor Legeforen. DOI: 10.4045/tidsskr.21.0074

Mottatt 26.1.2021, godkjent 16.2.2021.

(C) Tidsskrift for Den norske legeforening 2023. Lastet ned fra tidsskriftet.no 26. april 2023. 